\title{
DEVELOPMENT OF METHODS FOR MONITORING AND CONTROLLING POWER IN NUCLEAR REACTORS
}

\begin{abstract}
A. Z. Mesquita,
H. C. Rezende,

A. A. C. Santos,

and V. V. A. Silva

Serviço de Tecnologia de Reatores

Centro de Desenvolvimento da Tecnologia

Nuclear/Comissão Nacional de Energia

Nuclear (CDTN/CNEN)

Campus da UFMG, Pampulha,

Belo Horizonte, Brasil

amir@cdtn.br

hcr@cdtn.br

aacs@cdtn.br

vitors@cdtn.br

Received: November 07, 2013

Revised: November 19, 2013

Accepted: January 19, 2014

ABSTRACT

Power monitoring of nuclear reactors is normally done by means of neutronic instruments, i.e. by the measurement of neutron flux. The greater the number of channels for power measuring the greater is the reliability and safety of reactor operations. The aim of this research is to develop new methodologies for on-line monitoring of nuclear reactor power using other reliable processes. One method uses the temperature difference between an instrumented fuel element and the pool water below the reactor core. Another method consists of the steady-state energy balance of the primary and secondary reactor cooling loops. A further method is the calorimetric procedure whereby a constant reactor power is monitored as a function of the temperature-rise rate and the system heat capacity. Another methodology, which does not employ thermal methods, is based on measurement of Cherenkov radiation produced within and around the core. The first three procedures, fuel temperature, energy balance and calorimetric, were implemented in the IPR-R1 TRIGA nuclear research reactor at Belo Horizonte (Brazil) and are the focus of the work described here. Knowledge of the reactor thermal power is very important for precise neutron flux and fuel element burnup calculations. The burnup is linearly dependent on the reactor thermal power and its accuracy is important in the determination of the mass of burned ${ }^{235} \mathrm{U}$, fission products, fuel element activity, decay heat power generation and radiotoxicity. The thermal balance method developed in this project is now the standard methodology used for IPR-R1 TRIGA reactor power calibration and the fuel temperature measuring is the most reliable way of on-line monitoring of the reactor power. This research project primarily aims at increasing the reliability and safety of nuclear reactors using alternative methods for power monitoring.

Keywords: energy, power, nuclear reactor, safety, instrumentation.
\end{abstract}

\section{NOMENCLATURE}

$\mathrm{T} \quad$ Temperature, ${ }^{\circ} \mathrm{C}$

$\mathrm{q}$ Thermal power, $\mathrm{kW}$

$\mathrm{R}^{2} \quad$ coefficient of determination, dimensionless

$\dot{m} \quad$ flow rate of the coolant, $\mathrm{kg} / \mathrm{s}$

$\mathrm{C}_{\mathrm{p}}$ coolant specific heat at constant pressure, $\mathrm{kJ} /\left(\mathrm{kg} .{ }^{\circ} \mathrm{C}\right)$

$\mathrm{t}$ time, $\mathrm{s}$

$\mathrm{K}$ heat capacity constant, $\mathrm{kW} /{ }^{\circ} \mathrm{C}$

$\mathrm{V}$ water volume, $\mathrm{m}^{3}$

\section{Greek symbols}
$\Delta \quad$ difference
$\rho \quad$ coolant density, $\mathrm{kg} / \mathrm{m}^{3}$

\section{Subscripts}

w water

\section{INTRODUCTION}

Redundancy and diversity are two important criteria for power measurement in nuclear reactors. Other criteria such as accuracy, reliability and response speed are also of major concern. Power monitoring channels play a major role in safe reliable operation of nuclear reactors. Accurate power monitoring using advanced developed channels could make nuclear reactors a more reliable energy source and change public mind about this major energy resource (IAEA, 2008). The recent accidents in Fukushima reactors and its effects on the environment show the importance of developing new safety system.

The aim of this research is to develop new methodologies for on-line monitoring of nuclear reactor power using other reliable processes. One method uses the temperature difference between an instrumented fuel element and the pool water below the reactor core. Another method consists of the steady-state energy balance of the primary and secondary reactor cooling loops. Further method is by 
calorimetric procedure whereby the reactor power is monitored as a function of the temperature-rise rate and the system heat capacity constant. Another methodology, which does not employ thermal methods, is based on measurement of Cherenkov radiation produced within and around the core. The first three procedures, fuel temperature, energy balance and calorimetric, have been developed and experimentally validated in the IPR-R1 TRIGA nuclear research reactor at Nuclear Technology Development Center - CDTN (Belo Horizonte, Brazil) and are the focus of the work described here. The thermal balance method developed in this project is now the standard methodology used for IPR-R1 reactor power calibration, and power measuring by using the fuel temperature is the most reliable way of on-line monitoring of the reactor power (Mesquita, 2005).

\section{POWER MEASURING CHANNELS BY NEUTRONIC METHODS}

Power monitoring of nuclear reactors is always done by means of nuclear detectors, which are calibrated by thermal methods. The IPR-R1 TRIGA research reactor was originally equipped with four neutron-sensitive chambers mounted around the reactor core for flux measurement (nuclear channels).

The departure channel consists of a fission counter with a pulse amplifier and a logarithmic count rate circuit.

The logarithmic channel consists of a compensated ion chamber, whose signal is the input to a logarithmic amplifier, which gives a logarithmic power indication from less than $0.1 \mathrm{~W}$ to full power.

The linear channel consists of a compensated ion chamber, whose signal is the input to a sensitive amplifier and recorder with a range switch, which gives accurate power information from source level to full power on a linear recorder.

The percent channel consists of an uncompensated ion chamber, whose signal is the input to a power level monitor circuit and meter, which is calibrated in percentage of full power.

Unfortunately, the ionization chamber neutron detector measures the flux of neutrons thermalized in the vicinity of the detector. This signal is not always proportional to the integral neutron flux in the core and consequently to the core power. In addition, the response of a single nuclear detector is sensitive to the changes in the core configuration, particularly to the control rod position. This is important in the TRIGA reactor, which do not have distributed absorbers for reactivity control and whose criticality maintenance is done by insertion of control rods (Zagar et al., 1999).

In order to improve the power measurement system, three more channels using thermal procedures have been introduced in recent years. These new channels will be described below.

\section{POWER MEASURING CHANNEL USING FUEL AND POOL TEMPERATURE}

To evaluate the thermal hydraulic performance of the IPR-R1 TRIGA nuclear reactor, one instrumented fuel element was placed in the core for the experiments. The instrumented fuel is identical to standard fuel elements, but it is equipped with three chromel-alumel thermocouples, embedded in the zirconium pin centerline. One of the sensitive tips of the thermocouples is located at the center of the fuel section, while the other two are placed $25.4 \mathrm{~mm}$ above, and $25.4 \mathrm{~mm}$ below the center.

During the thermal hydraulic experiments it was observed that the temperature difference between the fuel element and the pool water below the reactor core (primary loop inlet temperature) did not change for the same power value. With the instrumented fuel element in the hottest fuel element position of the core, the power measured in the Linear Channel (with the values corrected by the calibration results) was plotted as a function of the temperature difference between the fuel and the primary loop inlet temperature. The polynomial expression relating the two values as obtained by Mesquita (2005) is:

$$
\begin{aligned}
\mathrm{q}=2 \times 10^{-5}(\Delta \mathrm{T})^{3}- & 0.0045(\Delta \mathrm{T})^{2} \\
+ & 0.7666 \Delta \mathrm{T}-2.4475
\end{aligned}
$$

Where $\mathrm{q}$ is the calibrated reactor thermal power, in $[\mathrm{kW}]$ and $\Delta \mathrm{T}$ is the difference between the average fuel temperature and the primary loop inlet temperature, in $\left[{ }^{\circ} \mathrm{C}\right]$. A coefficient of determination equal to one $\left(\mathrm{R}^{2}=1\right)$ was obtained. The equation was included in the data acquisition system and this new power measurement channel is now available for the IPR-R1 TRIGA reactor. After the experiments the instrumented fuel element was maintained in the core to monitor reactor power and core temperature in all reactor operations.

The reactor power measured by the conventional neutron channel and the above procedure were compared, showing high agreement between the two results. This channel has a fast response to power change and has been in operation since 2006.

\section{POWER MEASURING CHANNEL USING THERMAL BALANCE}

The reactor core is cooled by natural convection of demineralized light water in the reactor pool. Heat is removed from the reactor pool and released into the atmosphere through the primary cooling loop, the secondary cooling loop and one external cooling tower. Pool temperature depends on the reactor power, as well as on the external temperature, which affects heat dissipation in the cooling tower. The total power is determined by the thermal balance of cooling water flowing through the primary and 
secondary loops added to the calculated heat losses. These losses represent a very small fraction of the total power (about $1.5 \%$ of total).

The inlet and outlet temperatures are measured by two platinum resistance thermometers (PT-100) positioned at the inlet and outlet pipes of the primary and secondary cooling loops. The flow-rate in the primary loop is measured by an orifice plate and a differential pressure transmitter. The flow in the secondary loop is measured by a flowmeter. The pressure transmitter and the temperature measuring lines were calibrated and an adjusted equation was added to the data acquisition system. The steady state is reached after some hours of reactor operation, so that the power dissipated in the cooling system added to the losses should be equal to the core power. The thermal power dissipated in the primary and secondary loops is given by:

$$
\mathrm{q}_{\mathrm{cool}}=\dot{m} \mathrm{c}_{\mathrm{p}} \Delta \mathrm{T}
$$

Where $\mathrm{q}_{\text {cool }}$ is the thermal power dissipated in the loop $[\mathrm{kW}], \dot{m}$ is the flow rate of the coolant water in the loop $[\mathrm{kg} / \mathrm{s}], \mathrm{c}_{\mathrm{p}}$ is the specific heat of the coolant $\left[\mathrm{kJ} / \mathrm{kg}^{\circ} \mathrm{C}\right]$, and $\Delta \mathrm{T}$ is the difference between the inlet and outlet temperatures in the loop $\left[{ }^{\circ} \mathrm{C}\right]$. The data acquisition computer program calculates the power dissipated in the cooling loop using the collected data, and with the and $c_{p}$ values calculated as a function of coolant temperature. To calculate heat loss, a resistance thermometer (PT-100) was positioned inside the pool to measure the pool water temperature. A type $\mathrm{K}$ thermocouple was placed just above the pool surface to measure the air temperature at the reactor room. Two type $\mathrm{K}$ thermocouples were distributed around the pool, in holes in the reactor room floor, to measure the soil temperature. The power evolution in the primary and secondary loops during one reactor operation is shown in Fig. 1, and is now available in real time on the data acquisition system screen.

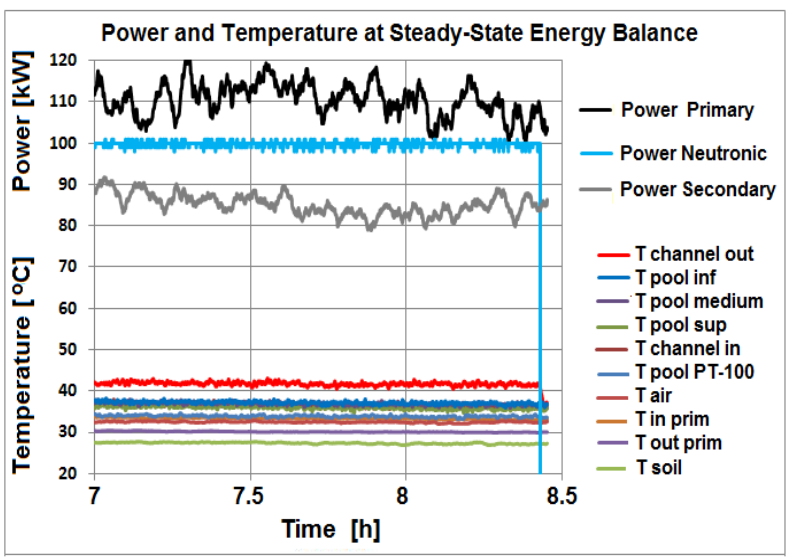

Figure 1. Thermal power evolution in the cooling system.

\section{THE CALORIMETRIC METHOD}

The calorimetric procedure is essentially the same whether it involves the calorimetric determination of heat equivalent of electrical energy. With the reactor operating at a constant power, the rate of temperature rise was determined. With a tank constant $(\Delta \mathrm{T}$ per unit power) calculated for the applicable heat content of the system, the reactor power was then determined from the measured rate of the temperature rise from operation of the reactor. The method is performed according to the following procedure (Zagar et al., 1999):

- Cover the reactor tank to increase the thermal isolation.

Operate the reactor at constant power with primary cooling system switched off.

- Record the temperature rise of the pool water, air and soil around the pool.

- $\quad$ Determine the temperature-rise rate $(\Delta \mathrm{T} / \Delta \mathrm{t})$.

- $\quad$ Calculate the reactor power as a function of temperature-rise rate.

Calculate the heat losses.

The basic formulation is:

$$
\mathrm{q}=\mathrm{K} \mathrm{dT} / \mathrm{dt} \text {, }
$$

Where $\mathrm{q}$ is the power and $\mathrm{K}$ is the experimentally determined heat capacity constant given by:

$$
\mathrm{K}=\rho \mathrm{V}_{\mathrm{w}} \quad \mathrm{C}_{\mathrm{p}}
$$

Where $\rho$ is the water density, $V_{w}$ is the water volume and $c_{p}$ is the water specific heat capacity. The reactor pool heat capacity constant can be calculated as well. In the first approximation, we can assume that the reactor pool temperature is constant throughout the pool and neglect all heat losses from the pool. We can approximate the reactor pool as an insulated "point" system. We can treat reactor pool as insulated when water temperature is close to air and soil temperatures. So the reactor heat capacity $\mathrm{K}$ can be simply calculated from wet pool volume $\mathrm{V}_{\mathrm{w}}$. For the TRIGA system the mass is mainly the water in the tank because of its large heat capacity. The product of the metal components mass times their individual heat capacity is too small compared to the heat content of the large body of water.

The reactor operated during a period of about 2.5 hours with the forced cooling system switched off and with an indication of $100 \mathrm{~kW}$ at the linear neutronic channel. The calculated average water volume $\mathrm{V}_{\mathrm{w}}$ during the experiment was $17.7 \mathrm{~m}^{3}$ and the heat capacity calculated was $\mathrm{K}=20.35 \mathrm{~kW} /{ }^{\circ} \mathrm{C}$. The thermophysical properties of water used in the calculation were for $38{ }^{\circ} \mathrm{C}$. The value was very close to the results obtained for the reactor TRIGA at Ljubljana, $\mathrm{K}=20.4 \mathrm{kWh} / \mathrm{K}\left(\mathrm{V}_{\mathrm{w}}=17.6 \mathrm{~m}^{3}\right)$, and for 
the reactor TRIGA at Vienna, $\mathrm{K}=19.1 \mathrm{kWh} / \mathrm{K}\left(\mathrm{V}_{\mathrm{w}}=\right.$ $16.5 \mathrm{~m}^{3}$ ) (Zagar et al., 1999).

The temperature rising rates measurement for all thermometers in the reactor pool during calorimetric power calibration are presented in Fig. 2. The thermal power obtained by this method had a great uncertainty (about $\pm 20 \%$ ).

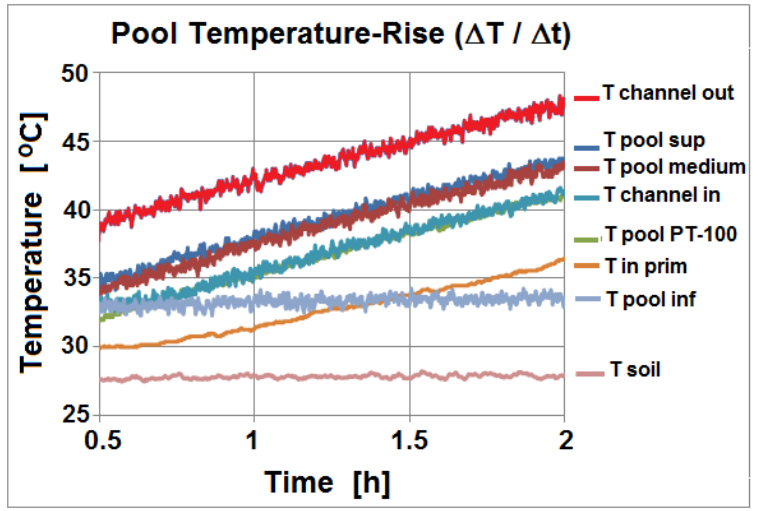

Figure 2. Temperature-rise rates during calorimetric power calibration procedure.

\section{CONCLUSIONS}

The aim of this paper is to present methodologies developed for on-line monitoring of nuclear reactor power using new reliable procedures. Three methodology, fuel temperature, energy balance and calorimetric, were implemented in the IPR-R1 TRIGA nuclear research reactor, and are the focus of the work described here.

The value of the thermal power obtained by the fuel temperature method has uncertainties of about $4 \%$. The heating of the thermocouple due to gamma rays is negligible because it has small mass and good thermal radiation equilibrium with the surrounding fuel. The heat balance in the primary loop, described here, is the standard procedure for calibrating the power of the IPR-R1 TRIGA Mark I nuclear reactor. This method has uncertainties of about $4 \%$.

For continuous monitoring of the thermal reactor power level, the instrumentation for temperature and flow signal measurement was incorporate in the data acquisition system (Mesquita et al., 2011).

The methodologies and graphical interfaces implemented in this project provide greater reliability and transparency in its operations. Besides allowing visualization in real-time, transmission through the internet or in the networks, the data is stored and can be made available to the authorities and to the public. Both methods using thermal balance and using the increase in fuel temperature are efficient and precise for obtaining the thermal power. The uncertainty values obtained do not differ from those obtained from conventional nuclear measuring channels using neutron flux.

\section{ACKNOWLEDGEMENTS}

The following institutions support this research project: Nuclear Technology Development Center (CDTN), Brazilian Nuclear Energy Commission (CNEN), Research Support Foundation of the State of Minas Gerais (FAPEMIG) and Brazilian Council for Scientific and Technological Development (CNPq).

\section{REFERENCES}

IAEA - International Atomic Energy Agency, 2008, On-line Monitoring for Improving Performance of Nuclear Power Plants Part 2: Process and Component Condition Monitoring and Diagnostics, Vienna, ISSN 1995-7807, No. NP-T1.2, STI/PUB/1323, ISBN 978-92-0-101208-1.

Mesquita, A. Z., Rezende, H. C., and Souza, R. M. G. P., 2011, Thermal Power Calibrations of the IPR-R1 TRIGA Reactor by the Calorimetric and the Heat Balance Methods, Progress in Nuclear Energy, Vol. 53, pp. 1-11.

Mesquita, A. Z., 2005, Experimental Investigation on Temperatures Distributions in a Research Nuclear Reactor TRIGA IPR-R1, Doctoral Thesis, Universidade Estadual de Campinas, São Paulo, SP.

Zagar, T., Ravnik, M., and Persic, A., 1999, Analysis of Reactor Thermal Power Calibration Method, in: International Conference Nuclear Energy in Central Europe'99, Portoroz, Slovenia. pp. 91-98. 